alternation. This is seen most easily in their star pattern, in which the two triangles predominate alternately. It is difficult or impossible to maintain the perception of one triangle, although if they had a cognitive origin, one would expect to be able to do so. Furthermore, an adaptation hypothesis can better account for the fact that the figure that is predominant at a given moment appears brighter. If adaptation takes place, it is reasonable that the less strongly adapted figure should be brighter. It thus seems premature to conclude that this phenomenon cannot eventually be accounted for by a physiological model.

\section{R. Cavonius}

Laboratory of Medical Physics and Netherlands Institute for Ophthalmic Research,

Herengracht 196,

Amsterdam, The Netherlands

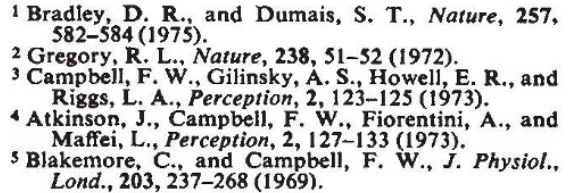

Bradley, Dumais and Heywood $M$. Petry RePly.--If Cavonius is correct in attributing the alternating organisations of our ambiguous configurations to the adaptation of "the channel that is most sensitive to that grating" (ref. 1), then such configurations should alternate independently of the viewer's knowledge of the possible organisations. It is not difficult, however, to construct figures which are highly resistant to alternations until the viewer is sensitised to the existence of alternative organisations. An example of such a figure, called the subjective Necker cube ${ }^{2}$, is presented in Fig. $1 a$. If observers are permitted to look at this figure for an extended period, most will eventually report seeing a cube overlying eight black disks and a white background (as in the unambiguous version of Fig. $1 b$ ). The whiter-thanwhite bars of the cube seen extending between the disks are, of course, illusory and are bounded by subjective contours.

Having achieved this cube-in-front organisation, most observers will maintain it indefinitely. If shown the unambiguous cube-in-back organisation of Fig. 1c, however, they then report being able to see the cube in Fig. 1a in that position as well, with subjective contours now bounding the interior edges of the 'holes' of the occluding surface rather than extending between the disks. Of course, once aware of these two organisations, the observer will then experience spontaneous alternation between the cube-in-front and cube-in-back. Although this might be accounted for by an adaptation hypothesis, such an hypothesis could not account for the initial absence of alternation. Furthermore, the observer can be 'cued' to a third possible organisation; that depicted in Fig. 1d. In this case, the observer will see both straight and curved subjective contours in Fig. $1 a$, because the 'straddled' organisation cued by Fig. 1d puts part of the cube in front and part in back. It seems

Fig. 1 Unambiguous versions of three possible organisations of the subjective Necker cube. $a$, Original ambiguous version; $b$, cube-in-front; $c$, cube-in-back; $d$, straddled.
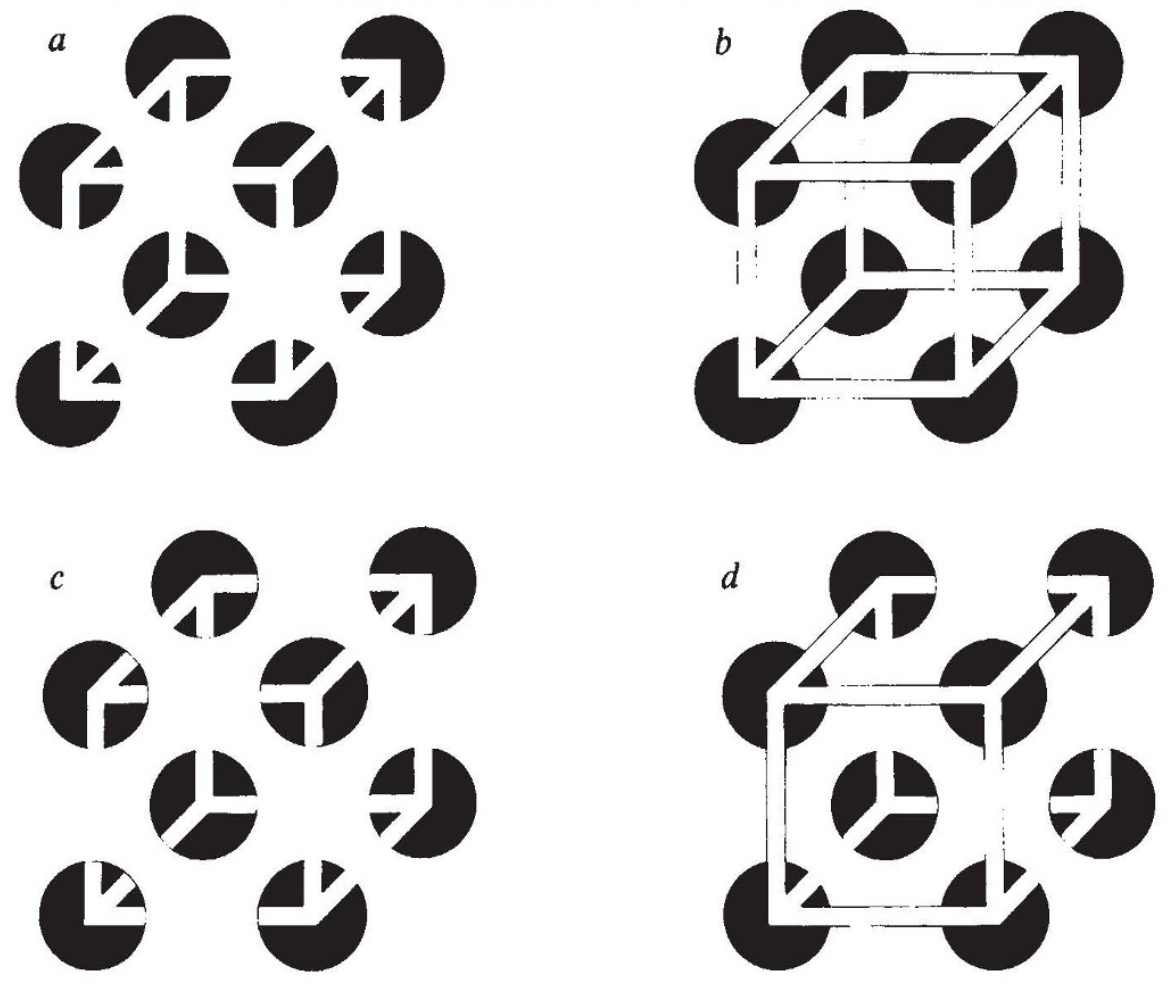

reasonable to suppose that perceptual phenomena which are strongly affected by set or expectation probably have a cognitive origin.

This view does not preclude the possibility of a physiological explanation of subjective contours. It does, however, require that any such explanation be able to incorporate the effects of cognitive variables (set, expectation, attention and so on) on the manner in which subjective contours are perceived in ambiguous displays.

Department of Psychology,

Bates College,

Lewiston, Maine 04240

1 Cavonius, C. R., Nature, 261, 77 (1976).

. logical Association, 92 (New York, 1975).

\title{
Insectivorous grouse
}

IT is, perhaps, unfortunate that we did not publish the results of incubating hens and other adult grouse separately in our paper on insects as food of adult grouse $^{1}$. In 1974, droppings from four incubating grouse on wet moors (at Moor House, Cumbria) were examined and contained similar proportions of insect remains (mainly tipulids) as did non-incubating birds. Similarly, females with young of different ages all showed tipulid remains in their droppings. Thus Moss and Watson ${ }^{2}$ can rest assured that incubating and brooding female red grouse do, at least on occasion, feed on tipulids in addition to vegetation.

Moss and Watson go on to state "there is no evidence that tipulids are ever in short supply on wet moors". We have information to the contrary ${ }^{3-5}$. In addition, both Molophilus ater and Tipula subnodicornis, the main species involved, fluctuate markedly in numbers and larval densities between $2,500 \mathrm{~m}^{-2}$ and $50 \mathrm{~m}^{-2}$ in the former and $250 \mathrm{~m}^{-2}$ and $5 \mathrm{~m}^{-2}$ in the latter have been documented by us on several occasions.

The relationship between grouse numbers and tipulid densities on wet moors is unknown. Even the cautious research workers might consider investigating the possibility of such a relationship, particularly since it has been shown that $N$ and $P$, which are in much higher concentrations in tipulids than in Calluna, are important to grouse ${ }^{\circ}$.

J. Butterfield

J. C. COULSON

Department of Zoology,

University of Durham,

Science Laboratories,

South Road, Durham DHI 3LE, UK

1 Butterfield, J., and Coulson, J. C., J. Anim. Ecol., 44, 601 (1975).

2 Moss, R., and Watson, A., Nature, 259, 250 (1976).

3 Coulson, J. C., J. Anim. Ecol., 31, 1 (1962).

Coulson, J. C., Trans. R. ent. Soc. Lond., 111, 157 (1959).

Coulson, J. C., and Whittaker, J. B., in Ecology of Some Moors and Montaine Grasslands (Springer,

6 Moss, R.,J. Anim. Ecol., 41, 411 (1972). 